\title{
IR-Signature of the MULDICON Configuration Determined by the IR-Signature Model MIRA
}

Erwin Lindermeir ${ }^{*}$, Markus Rütten ${ }^{\dagger}$

DLR - German Aerospace Center ${ }^{*}$ Remote Sensing Technology Institute tInstitute of Aerodynamics and Flow Technology

AIAA 2018, Atlanta, USA June 26, 2018

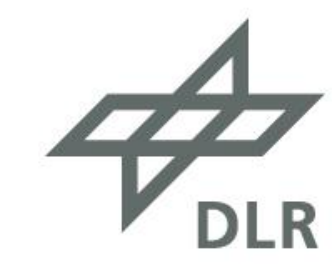




\section{Outline}

- The IR-Signature Model MIRA - Overview

- Application to IR-Signature Predictions for the MULDICON UCAV (NATO AVT-251)

- Summary 


\section{IR-Signature Model MIRA}

\section{Model for InfraRed Scene Analysis}

\section{Requirements}

- Modeling of emission and reflection

- Radiative transfer in complex shaped exhaust duct and inlet

- Arbitrarily shaped exhaust gas

- Interference of exhaust gas and flow around aircraft

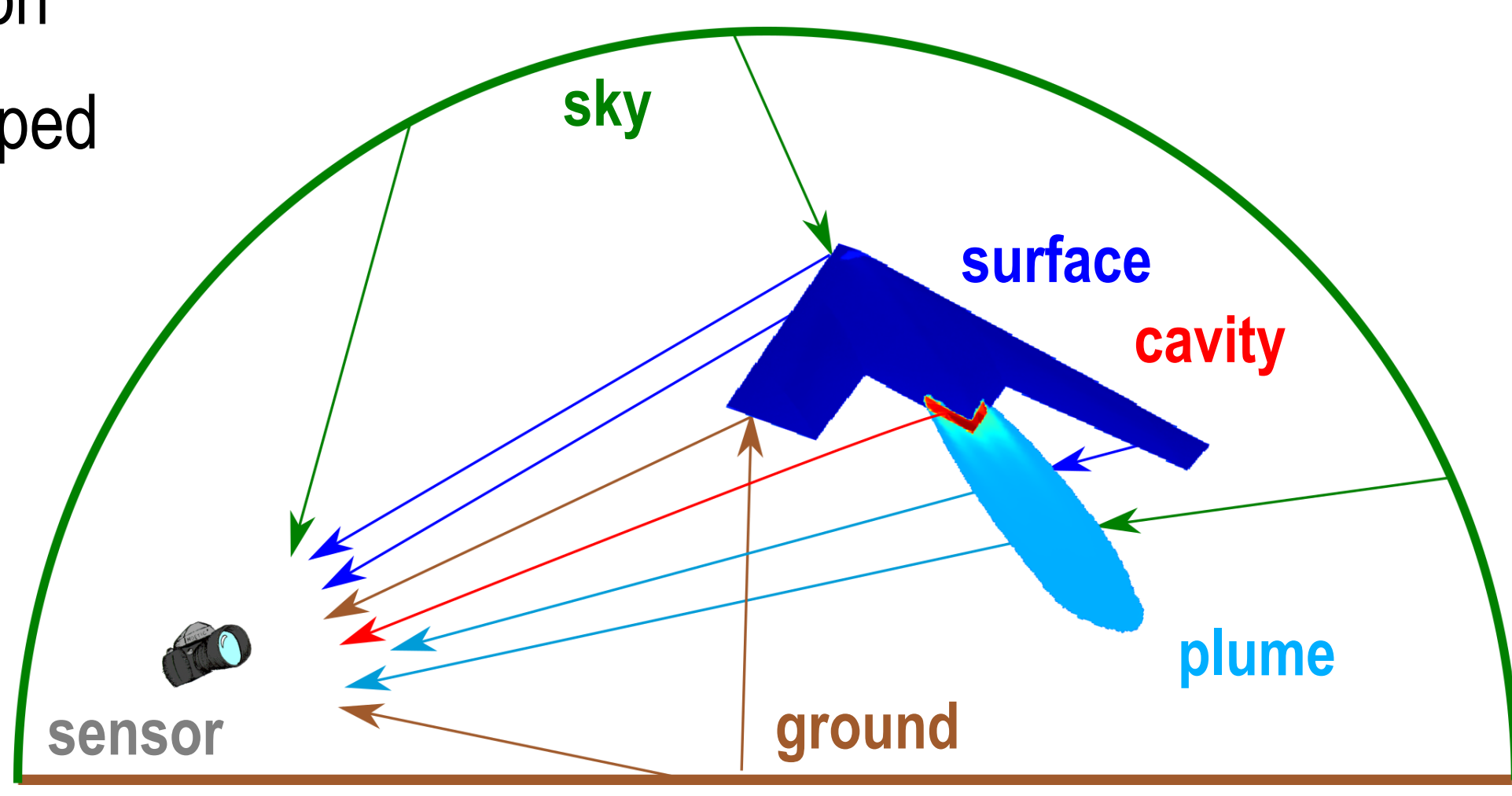




\section{MIRA - Reflections}

Method: Ray-tracing and Mote Carlo integration

Direct irradiance (one reflection):

Simple method:

Directions of incidence from BRDF* OR radiance distribution on surfaces and integrate.

MIRA: Multiple importance sampling (MIS):

Directions of incidence from BRDF AND radiance distribution on surfaces and weight contributions

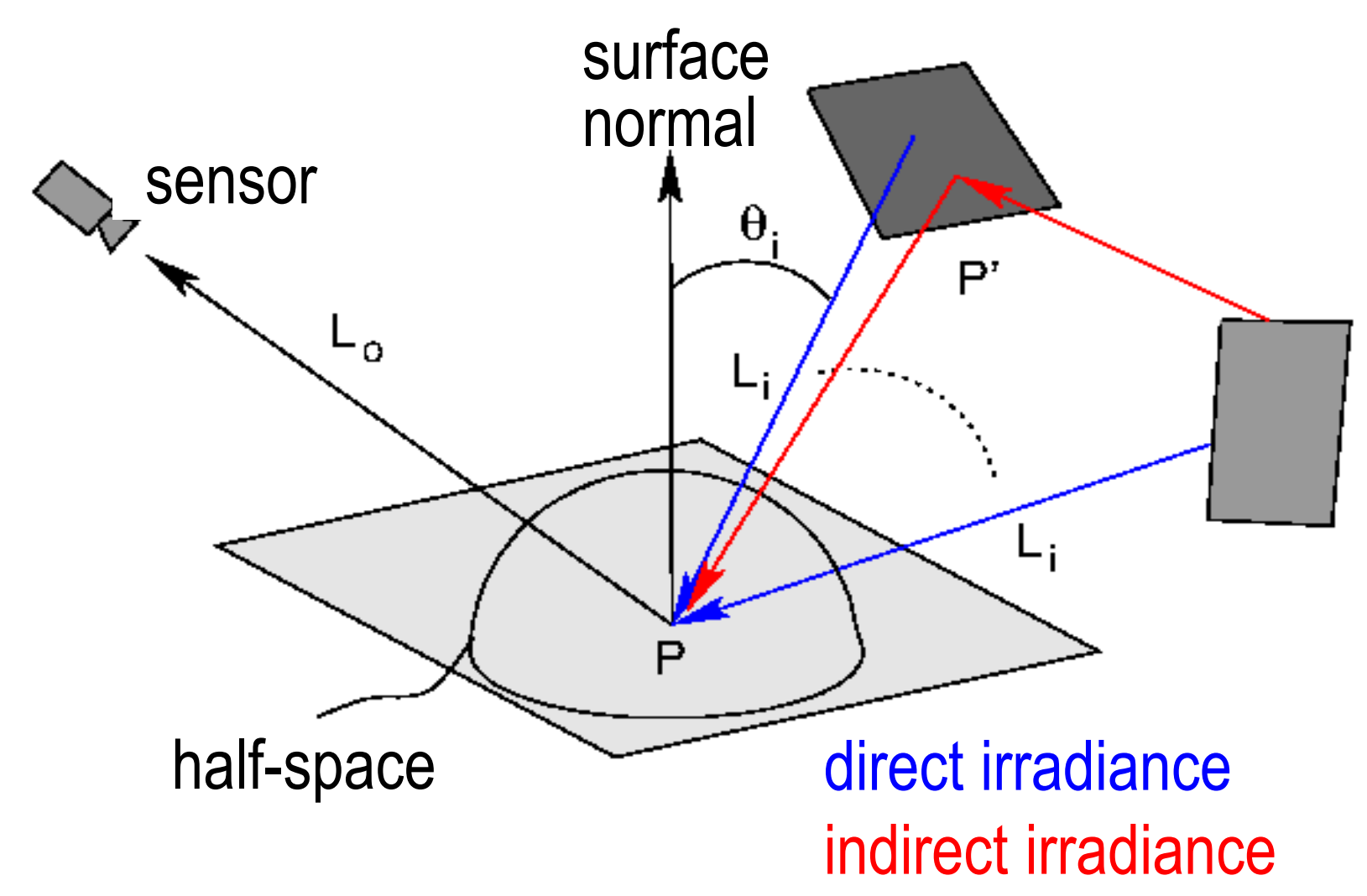

${ }^{*} \mathrm{BRDF}=\mathrm{Bi}$-directional reflection distribution function 


\section{Efficiency of Multiple Importance Sampling}

Cylinder (emissivity $\varepsilon=1, T=400 \mathrm{~K}$ ) in front of diffuse reflecting plate $(\varepsilon=0.6, \mathrm{~T}=300 \mathrm{~K})$

MIRA (simple)

256 rays per pixel, compute time: $22.5 \mathrm{~s}$

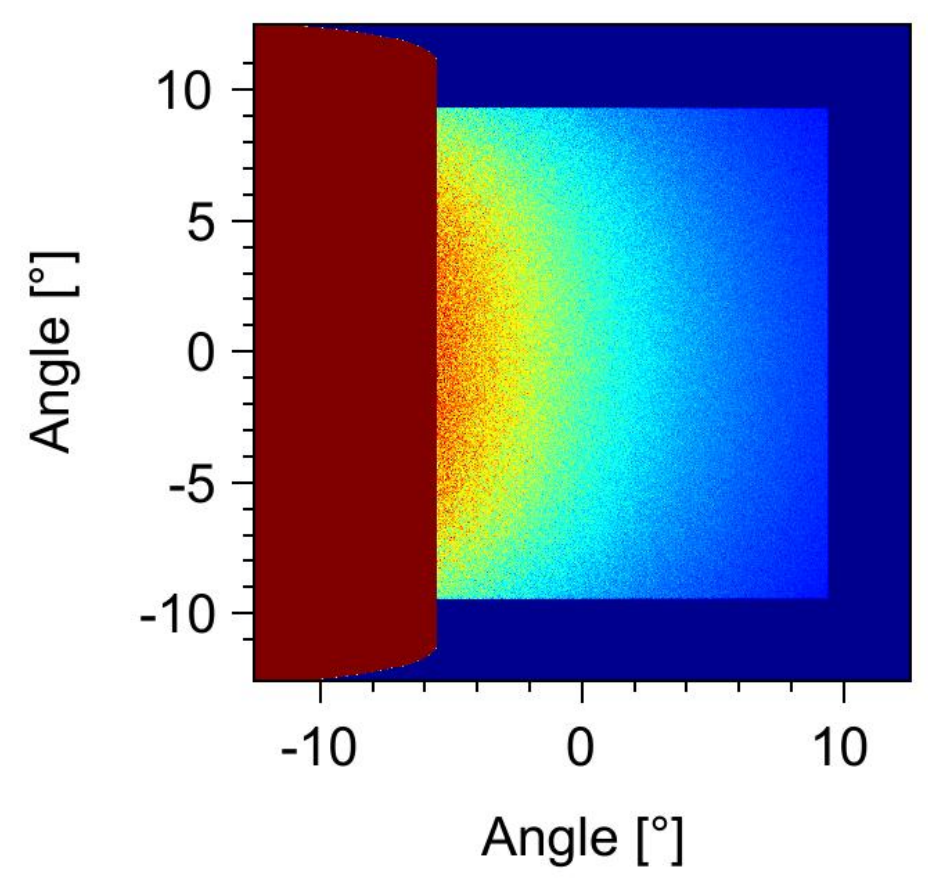

Radiance Temperature $[\mathrm{K}]$

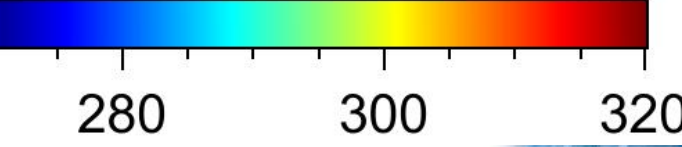

MIRA (MIS)

4 rays per pixel, compute time: $5.6 \mathrm{~s}$

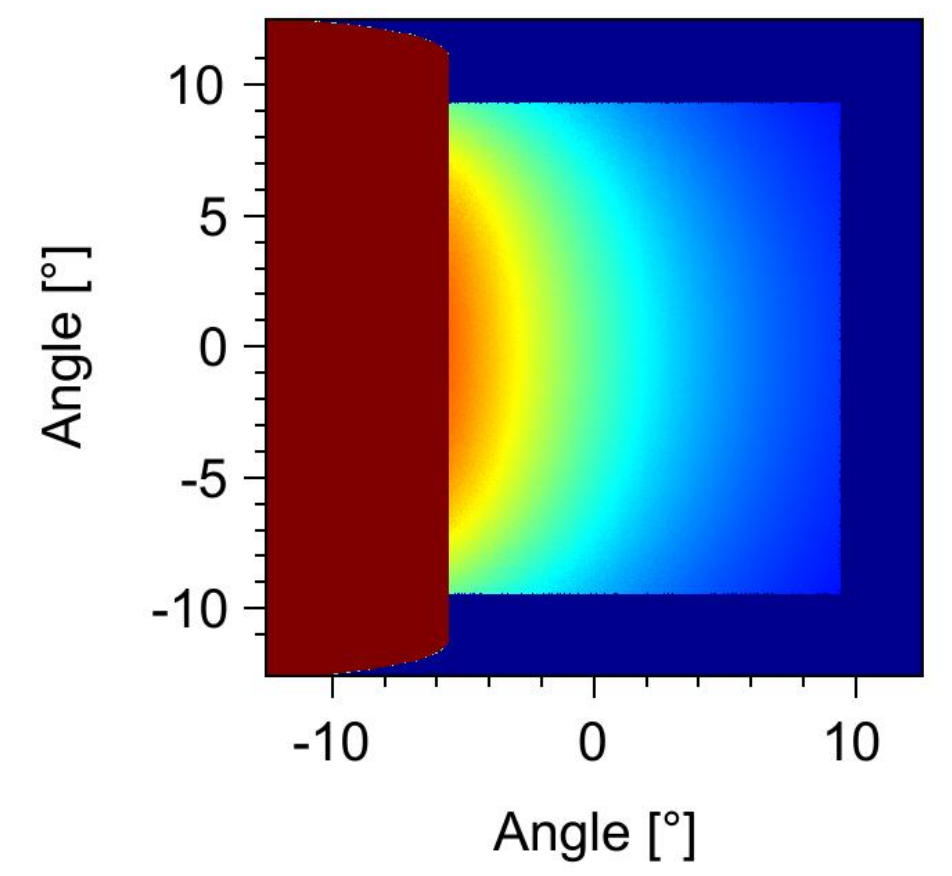

Radiance Temperature $[\mathrm{K}]$ 


\section{Modeling Multiple Reflections}

\section{Path-Tracing}

- Construction of „paths“ starting from the camera based on BRDF

\section{Bi-directional Path-Tracing}

- Construction of sub-paths starting from the camera and from (strong) radiators

- Connection of sub-paths of various lengths

\section{Common}

- Direct irradiance calculation at each intersection with geometry
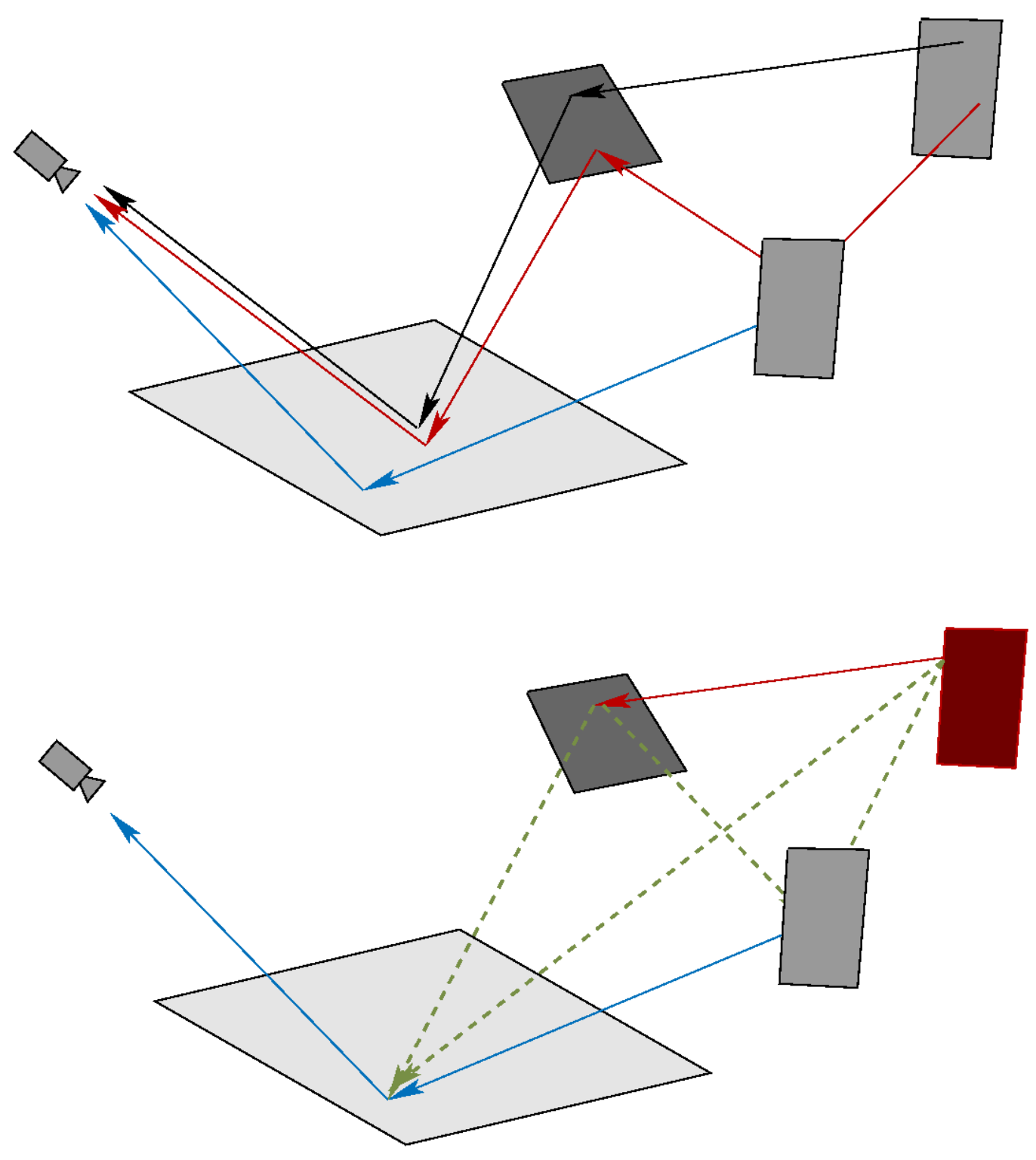


\section{IR-Signature Model MIRA}

\section{Further Capabilities}

- Spectral Range: 2 - $20 \mu \mathrm{m}$

- Optimized sample generation: Low discrepancy sampler (and others)

- Interface to DLR TAU code to include CFD results (exhaust gas)

- Atmosphere and ground modeled by coupling to MODTRAN

- Terrain model to permit real landscape using a DEM (digital elevation model) and a surface classification.

- Output: Images, radiance spectra (a/c skin, exhaust duct, plume, background,...), contrast radiant intensity and irradiance 


\section{MIRA IR-Signature Predictions to Improve the exhaust duct of MULDICON}

\section{MULDICON}

- Generic UCAV to demonstrate a multidisciplinary design approach

- Used in NATO AVT-251 and DLR project MEPHISTO

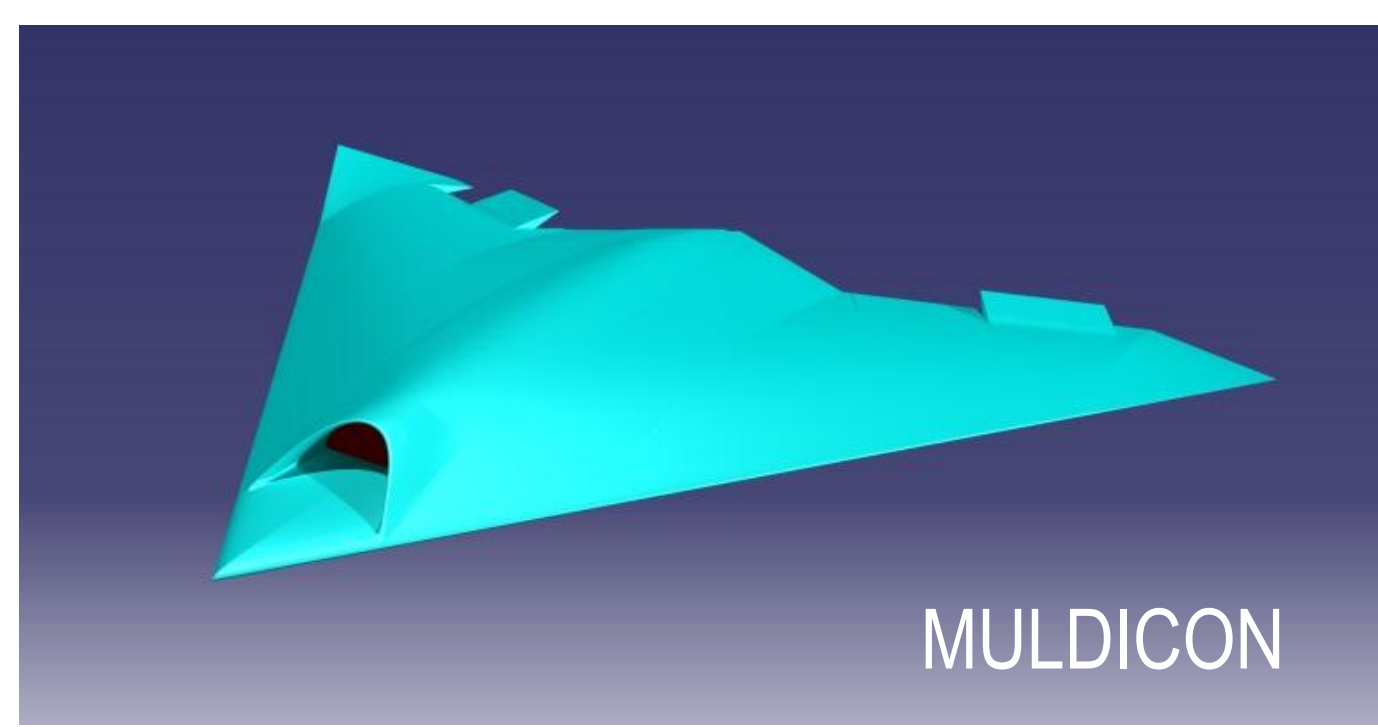

Courtesy of A. Schütte, DLR 


\section{Exhaust Duct Outer Shape}

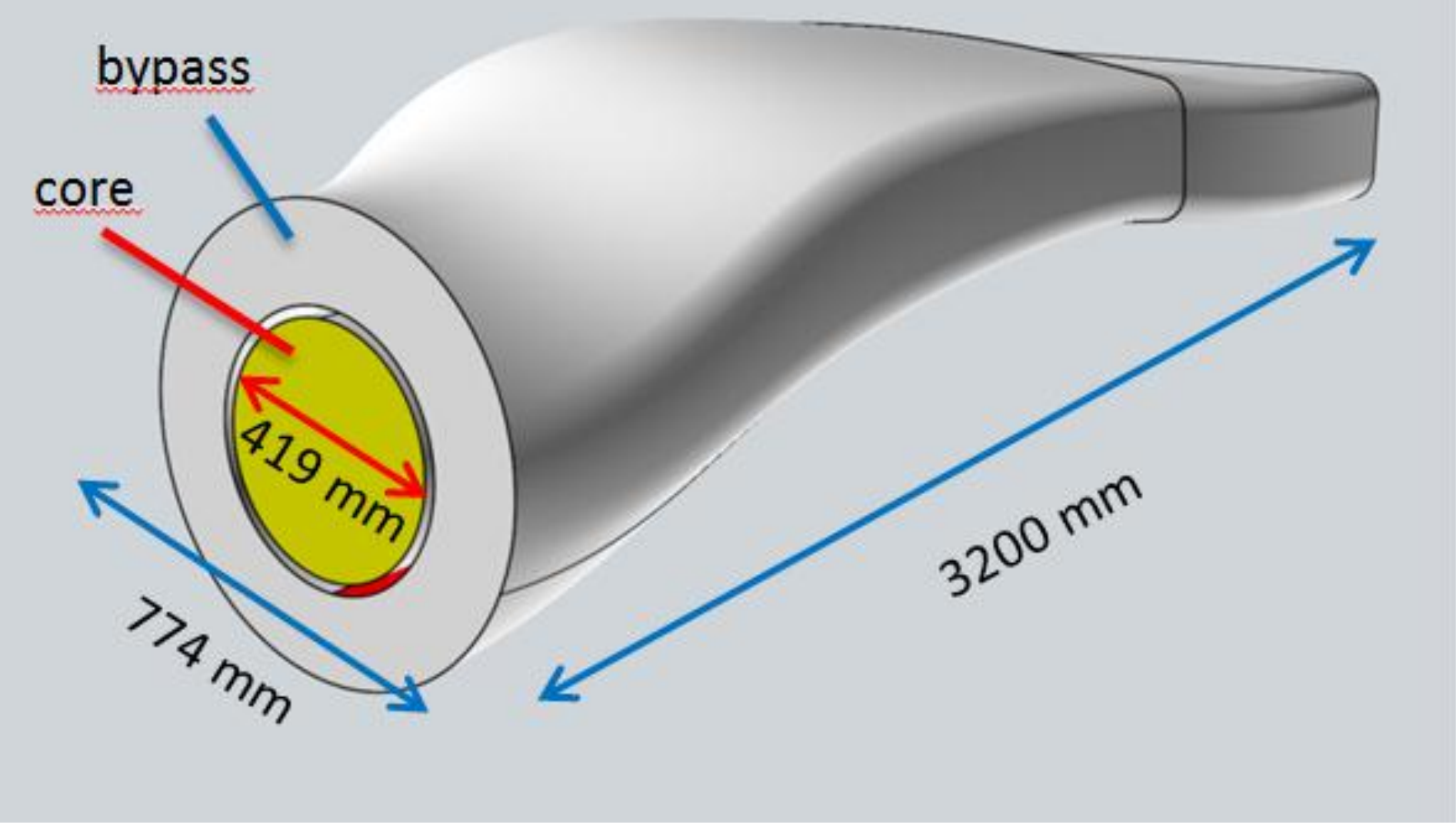

$4_{\mathrm{DLR}}^{4}$ 


\section{IR-Signature Comparison - View from below}

View: Off-tail angle $30^{\circ}$, elevation $-25^{\circ}$, distance $1 \mathrm{~km}$, background clear sky Velocity Mach 0.8, altitude $11 \mathrm{~km}$
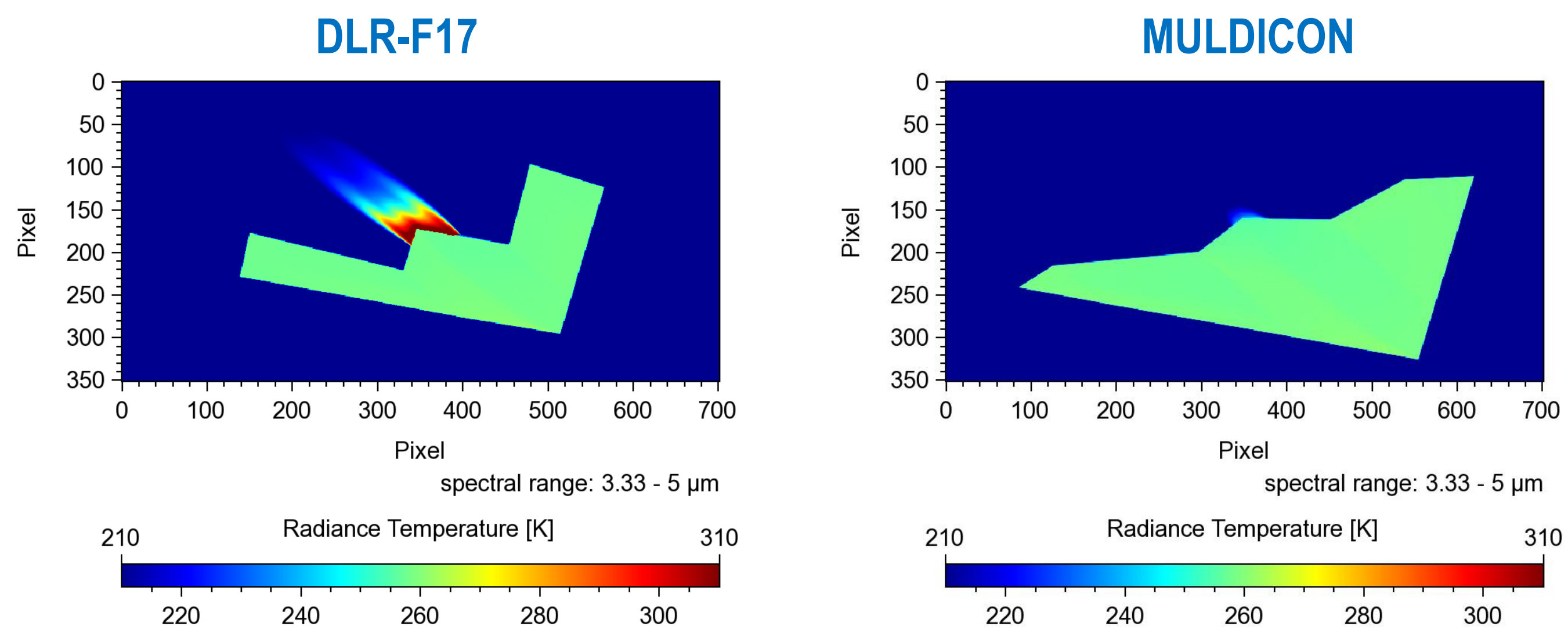


\section{IR-Signature Comparison - View from above}

View: Off-tail angle $30^{\circ}$, elevation $25^{\circ}$, distance $1 \mathrm{~km}$, homogeneous background Velocity Mach 0.8, altitude $11 \mathrm{~km}$
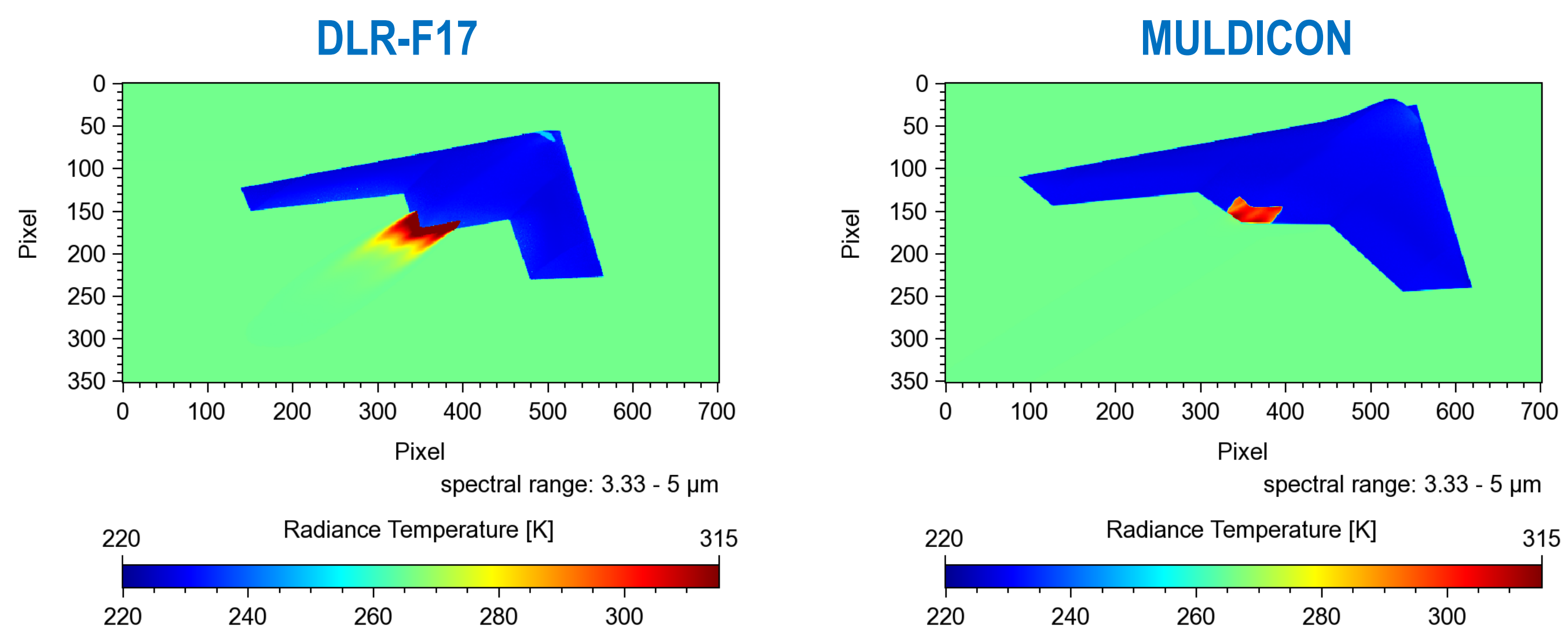


\section{IR-Signature of MULDICON at altitude $5 \mathrm{~km}$}

\section{Velocity Mach 0.8 , distance $5 \mathrm{~km}$, homogeneous background}

Off-tail angle $165^{\circ}$, elevation $25^{\circ}$
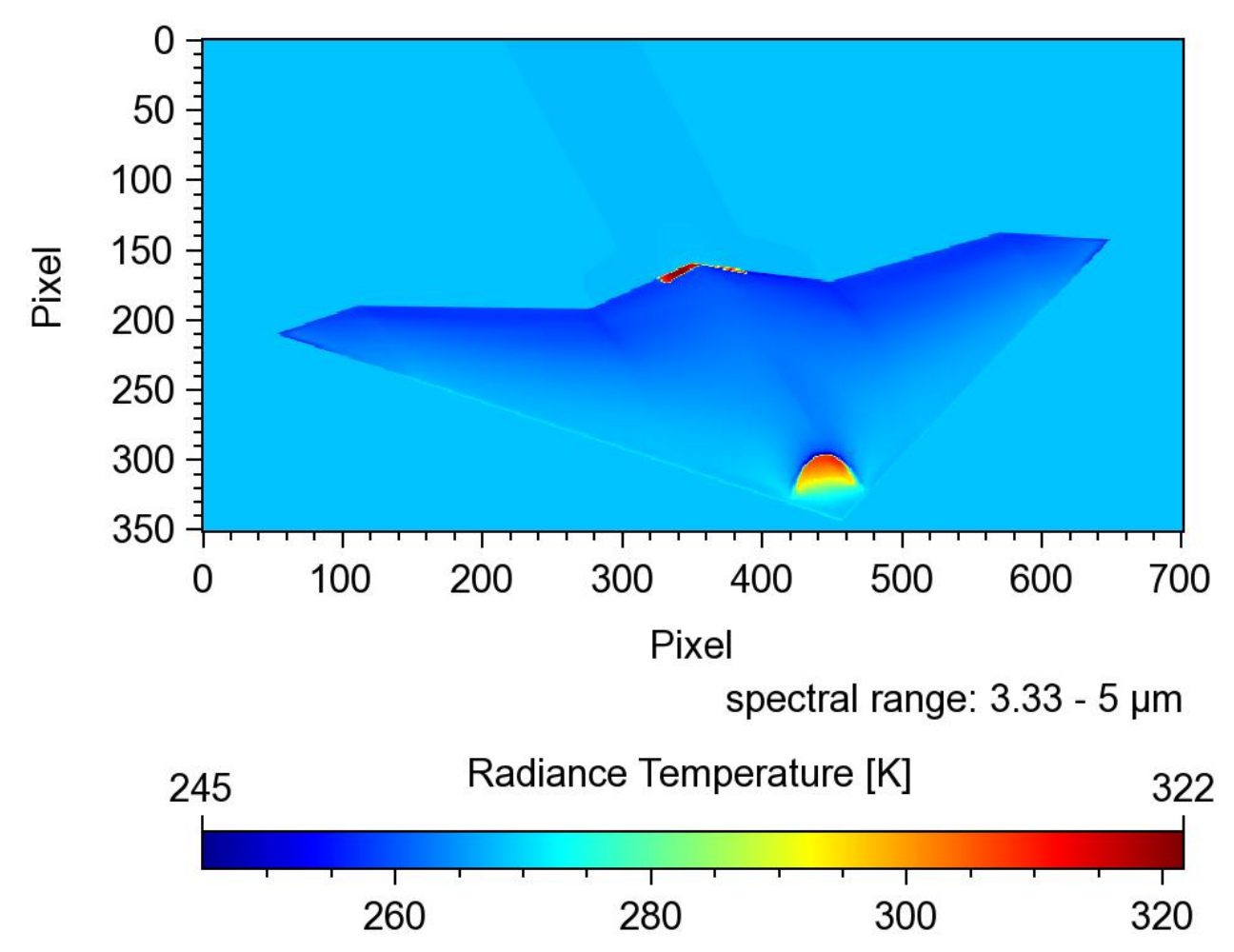

Off-tail angle $30^{\circ}$, elevation $-25^{\circ}$
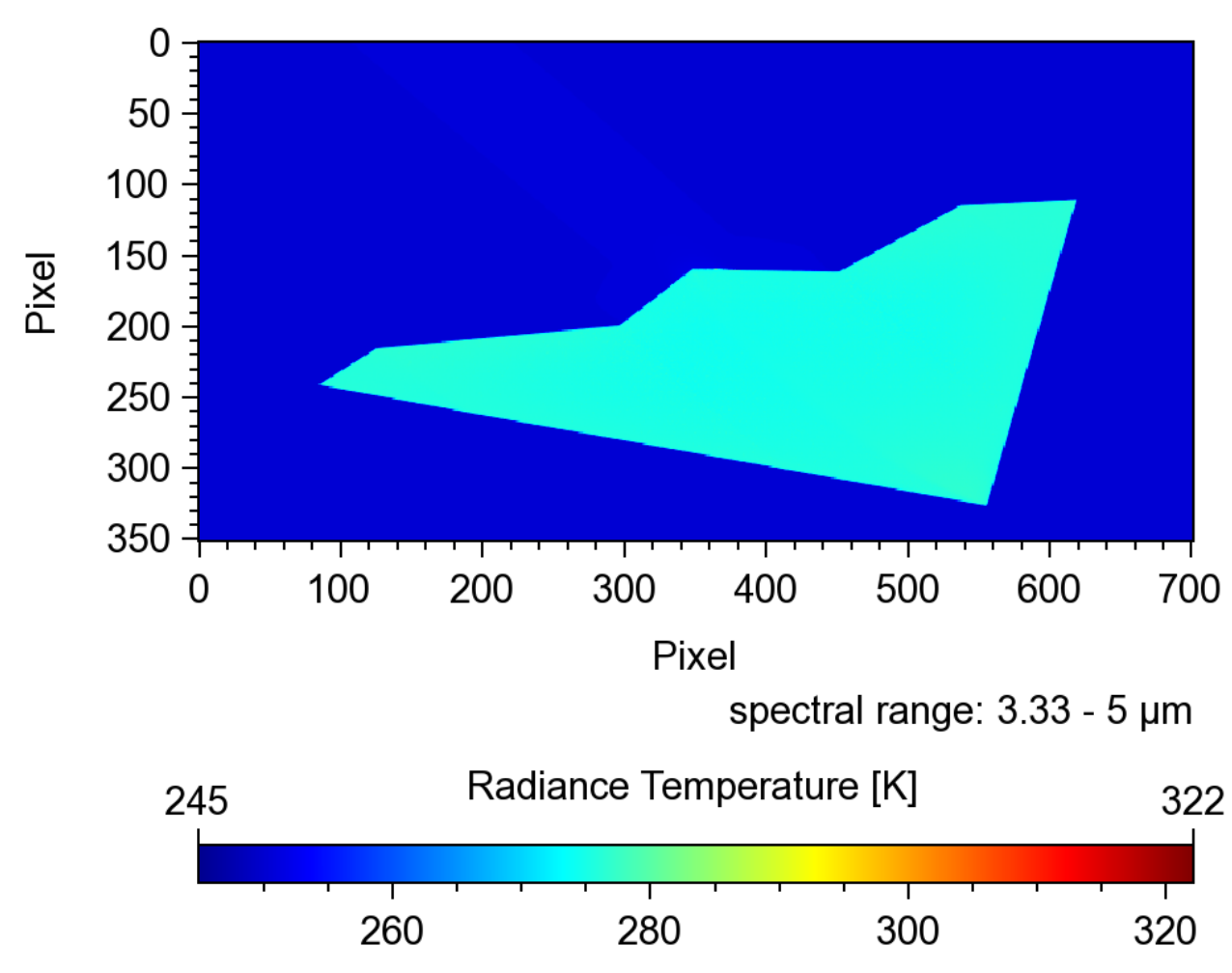


\section{MIRA's Terrain Model}

\section{Purpose}

Improve realism by a structured background

\section{Current state}

First Version: DEM + Classification

\section{Scene:}

MULDICON in front of Mt. Brocken in the Harz area of Germany

Data:

DEM Area: 135 km x 110 km

Classification derived from satellite data (Source: DLR's German Remote Sensing Data Center)

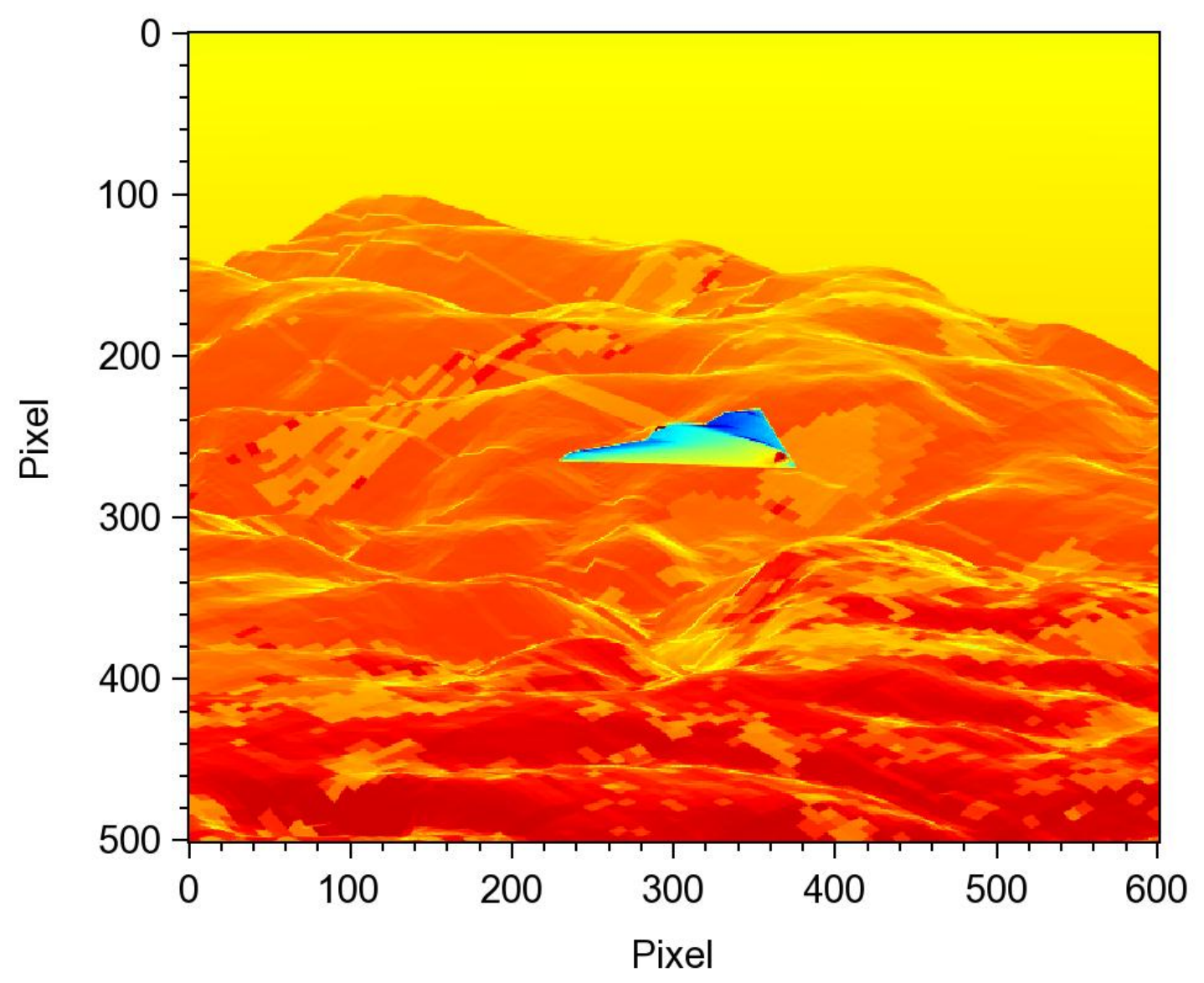

spectral range: $3.33-5 \mu \mathrm{m}$

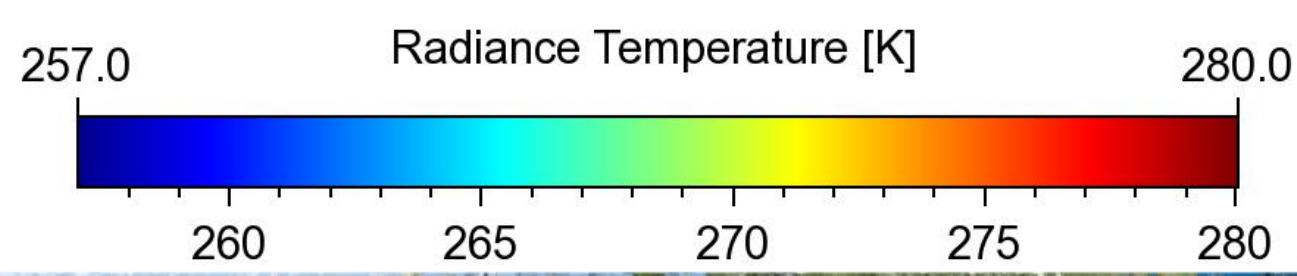




\section{Summary and Outlook}

\section{IR-Signature Model MIRA}

- Introduction of the IR-Signature Model MIRA

- Requirements, treatment of multiple reflections, terrain model

\section{MULDICON design}

- Application of MIRA to aid the design (exhaust duct) by IR-signature predictions

- Result: Exhaust gas emissions minimized, but skin reflection/emission problematic

\section{Next Steps}

- MIRA: Improved terrain model + structured sky (clouds)

- Investigations to lower the IR emission of MULDICON's airframe 